\title{
A Review: Devices used for Detecting Diabetic Autonomic Neuropathy
}

\author{
Supriya Mangalpalli ${ }^{1}$, Kanchan Gorde ${ }^{2}$ \\ ${ }^{1}$ Student, Department of Electronics, Terna Engineering College, Nerul (East), India \\ ${ }^{2}$ Assistant Professor, Department of Electronics, Terna Engineering College, Nerul (East), India
}

\begin{abstract}
Diabetic Autonomic neuropathy is serious complication that is causing mortality. The aim of this study is to provide detailed discussion related to different screening tools used for early detection of DAN which can be detected by the visual acuity parameters tracked by using LEDs of color blue, white, red and green which are continuously turned $O N$ and OFF and with two different intensities $50 m c d$ and $500 \mathrm{mcd}$ for stimulation of pupils which are captured by camera on spectacle mounted assembly. The designs are wearable devices, which comprises of ccd or noir camera, to detect visual acuity parameters consisting of pupil dilation, constriction and pupil diameter The beam splitter is used to filter the light captured which is provided to microcontroller for processing. These devices work as simple screening tool to avoid hazardous effects due to diabetic autonomic neuropathy, especially for patients with undiagnosed cardiac autonomic neuropathy which raises mortality rate. The pupil dynamics analysis has the potential for supporting such a screening approach. The pupil dynamics help in detecting the neurological disorders especially functioning of autonomic nervous system which handles functioning of cardiovascular, gastrointestinal, vision etc. Hence these are effective and prick-free diagnosis of pupil parameters give information about autonomic neuropathy before it affects functioning of prime organs and also gives details about severity of Type-2 diabetes.
\end{abstract}

Keywords: Raspberry Pi NoIR camera module,Raspberry Pi B+, pupil, Diabetic autonomic neuropathy

\section{Introduction (Cardiac Autonomic Neuropathy)}

Diabetic autonomic neuropathy (DAN) is a serious complication of diabetes which causes hazardous effects on patients. Despite its relationship to an increased risk of cardiovascular mortality and its association with multiple symptoms and impairments, the significance of DAN has not been fully appreciated. The reported prevalence of DAN varies widely depending on the cohort studied and the methods of assessment. In randomly selected cohorts of asymptomatic individuals with diabetes, $20 \%$ had abnormal cardiovascular autonomic function. DAN frequently coexists with other peripheral neuropathies and other diabetic complications, but DAN may be isolated, frequently preceding the detection of other complications. Perhaps one of the most overlooked of all serious complications of diabetes is CAN . According to team of scientists Aaron I. Vinik, Raelene E. Maser,Braxton D. Mitchell and Roy Freeman CAN results from damage to the autonomic nerve fibers that innervate the heart and blood vessels and results in abnormalities in heart rate control and vascular dynamics. Reduced heart rate variation is the earliest indicator of CAN Cardiovascular autonomic neuropathy (CAN) is the most studied and clinically important form of DAN. CAN is readily performed in the average clinic, hospital, or diagnostic center with the use of available technology. Measurement of HRV at the time of diagnosis of type 2 diabetes and within 5 years after diagnosis of type 1 diabetes (unless an individual has symptoms suggestive of autonomic dysfunction earlier) serves to establish a baseline, with which 1-year interval tests can be compared. Regular HRV testing provides early detection and thereby promotes timely diagnostic and therapeutic interventions.

\section{Diabetic Retinopathy}

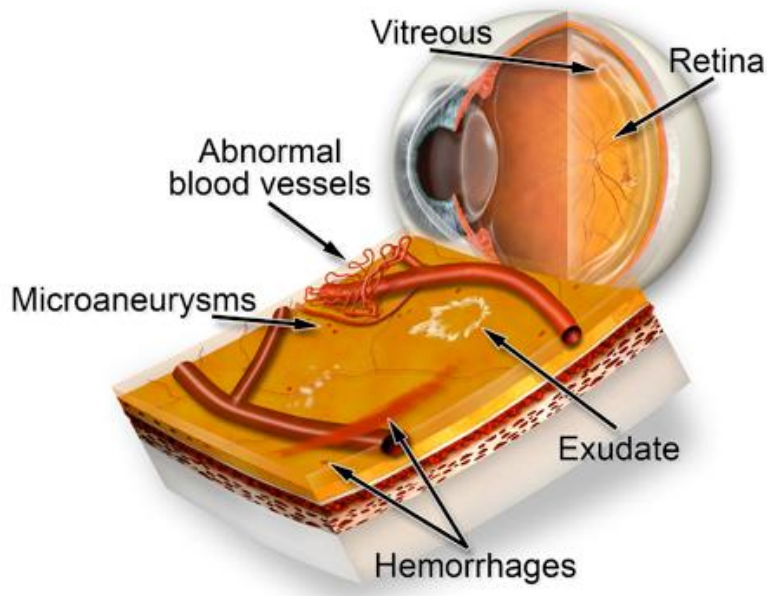

Figure 1: Introduction of Disease

These studies struck me with idea of creating wearable device which will be mounted on spectacle for early diagnosis of cardiovascular autonomic neuropathy (CAN) by diagnosis of pupil parameters.

\section{Comparison with Available Ideas of Pupilometers}

The screening tool for analyzing the visual acuity parameters for early detection of DAN was invented by many researchers. After reviewing and studying many research papers the limitations in each device invented by researchers has been tried to overcome in this study paper. The aim of this paper was to reduce to cost and improve the efficiency and reliability of the device to greater extent by providing instant results and fast treatment of the disease. 


\section{International Journal of Science and Research (IJSR) \\ ISSN (Online): 2319-7064}

Index Copernicus Value (2013): 6.14 | Impact Factor (2014): 5.611

1) An Approach to the Assessment of Diabetic Neuropathy Based Dynamic Pupillometry : The screening tool consists of CCD camera for capturing pupil images, IR LEDS to provide high pupil contrast, A built-in timing control based microcontroller (PIC16F873), Pentium IV $3 \mathrm{GHz}$ Notebook with PCMCIA frame grabber to record and process pupil images.
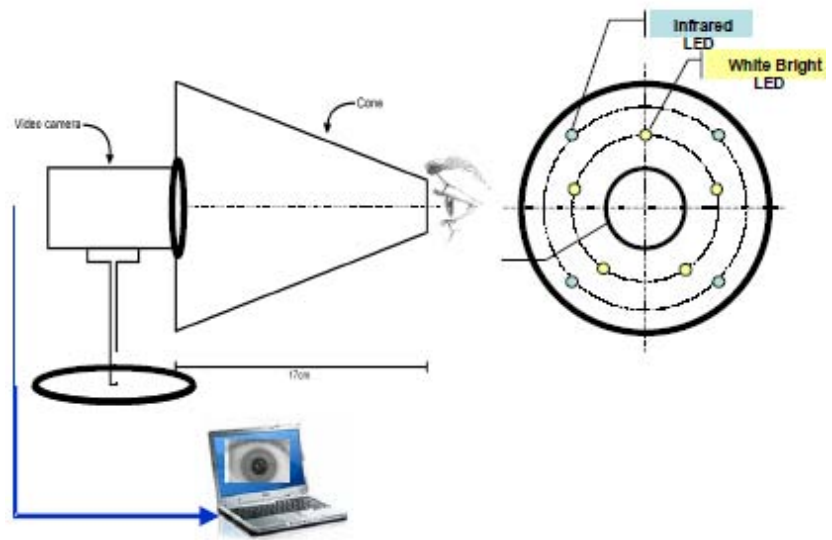

Figure 1: Setup of the pupil stimulator \& Response recorder instrument developed to perform in vivo experiments

2) A simple portable polychromatic pupillometer for human eye annoyance measurement :

The device consist of 3 main circuits: CCD camera

- Optical head - Plays an important role by providing feedback control to RGB LEDs Drivers. Consists of 2 voltage regulators, low pass filter and analog mosfet switch.

- Control Electronics - Main function is conversion of analog signals of RGB from optical head and amplification of those signals. It consists of frame grabber and battery pack.

- Arduino Module - Generating digital signals for controlling flicker characteristics of LEDs

- Software - Labview/ Matlab used for providing GUI to control flicker characteristics by regulating frequency, duty cycle and intensity.

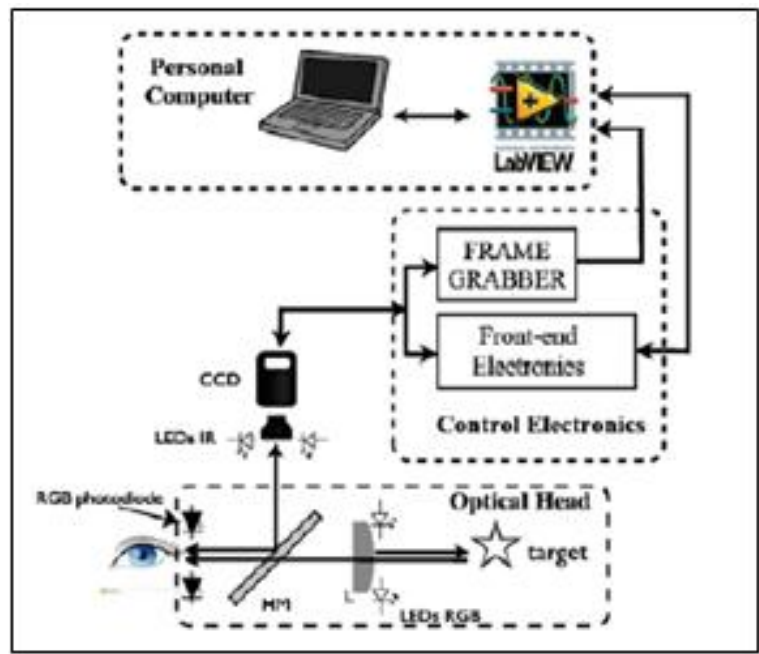

Figure 3: Setup of Screening Tool

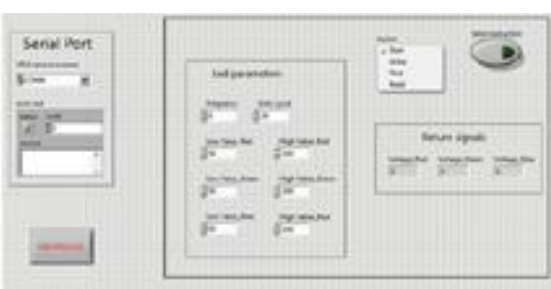

Figure 4: Lab-view used for controlling flicker characteristics

3) An open-source, FireWire camera-based, Labviewcontrolled image acquisition system for automated, dynamic pupillometry and blink detection. (Open source in title relate to free use of labview software codes for estimating pupillary and eyelid parameters allowing end users to use the software or modify it to suit their own needs).

Hardware - FireFly MV camera (consist of progressive scan CMOS) with 4- pin GPIO for device controlling and powering, Desktop computer, and illumination source.

Software - Labview 8.5 used for image acquisition with two software add-ons

- Visual development module 8.5- for image processing.

- NI-IMAQdx driver library - for handling low interfacing with IEEE1394 (FireWire) camera bus.

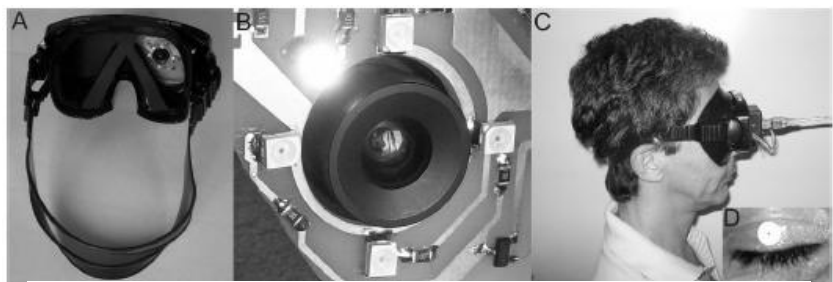

Figure 5: Setup of Device for analyzing pupil dynamics

4) Development of a Remote Pupillometer System for Non-Invasive, Distant Analysis :

Hardware output - Near IR illumination source i.e. two parallel rings consisting of IR LEDs, analog NIR camera (with telecentric lens and bandpass filter which complements illumination source wavelength), personal computer with frame grabber (ALTA-ANI Bitflow Inc.)

Software - MATLAB (implements algorithms to calculate diameter of eye)

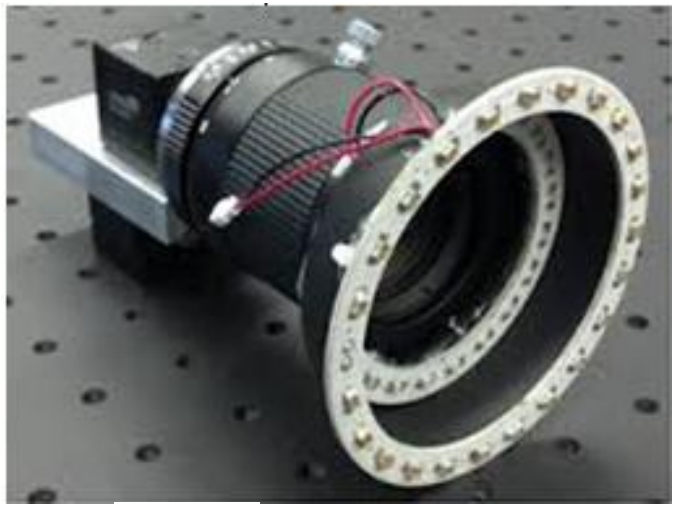

Figure 6: NIR sensitive camera 
International Journal of Science and Research (IJSR)

ISSN (Online): 2319-7064

Index Copernicus Value (2013): 6.14 | Impact Factor (2014): 5.611

\begin{tabular}{|c|c|c|c|}
\hline $\begin{array}{l}\text { Sr. } \\
\text { No. }\end{array}$ & Title of Research Paper & Output & Limitations \\
\hline 1. & $\begin{array}{c}\text { An Approach to the Assessment } \\
\text { of Diabetic Neuropathy Based } \\
\text { Dynamic Pupillometry }\end{array}$ & $\begin{array}{l}\text { Fig. 2. Pupil response and parameters measured (1-Latency time to reach } \\
\text { the plateau, 2-Latency time to the beginning of constriction, 3-Duration of } \\
\text { constriction, 4-Latency time to maximum constriction, 5-Radius of pupil } \\
\text { before flash, 6-Radius of pupil at maximum constriction, 7-Radius of pupil } \\
\text { at reaching the plateau). }\end{array}$ & $\begin{array}{l}\text { Device needs separate frame } \\
\text { grabber to process image. } \\
\text { Many pupil parameters are } \\
\text { calculated that increases } \\
\text { complexity of the analysis of } \\
\text { required parameters. }\end{array}$ \\
\hline 2. & $\begin{array}{c}\text { A simple portable } \\
\text { polychromatic pupillometer for } \\
\text { human eye annoyance } \\
\text { measurement }\end{array}$ & $\begin{array}{l}\text { (a) } \\
\text { (c) } \\
\text { Pupil diameter as function of flicker frequency }\end{array}$ & $\begin{array}{l}\text { High end use of hardware which } \\
\text { makes the device bulky and non- } \\
\text { reliable as more usage of PCB } \\
\text { circuits results in more voltage } \\
\text { and current fluctuations hence not } \\
\text { providing proper/reliable output. } \\
\text { Labview and Matlab softwares } \\
\text { are very costly making device } \\
\text { expensive }\end{array}$ \\
\hline 3. & $\begin{array}{c}\text { An open-source, FireWire } \\
\text { camera-based, Labview- } \\
\text { controlled image acquisition } \\
\text { system for automated, dynamic } \\
\text { pupillometry and blink } \\
\text { detection. (Open source in title } \\
\text { relate to free use of labview } \\
\text { software codes for estimating } \\
\text { pupillary and eyelid parameters } \\
\text { allowing end users to use the } \\
\text { software or modify it to suit } \\
\text { their own needs). }\end{array}$ & Comparison between manual and automatic measurement & $\begin{array}{l}\text { IEEE1394 specifications } \\
\text { recommend voltage supply range } \\
\text { between } 8-35 \mathrm{~V} \text { which is } \\
\text { incompatible with circuit } \\
\text { adaptation. } \\
\text { Labview } 8.5 \text { - Use of this } \\
\text { software increase the cost of the } \\
\text { device. }\end{array}$ \\
\hline 4. & $\begin{array}{l}\text { Development of a Remote } \\
\text { Pupillometer System for Non- } \\
\text { Invasive, Distant Analysis }\end{array}$ & Image obtained by MATLAB for analysis of pupil & $\begin{array}{c}\text { Use of MATLAB software } \\
\text { increases cost and reduces speed } \\
\text { of image acquisition. } \\
\text { And quality of image obtained is } \\
\text { not better enough for analysis. }\end{array}$ \\
\hline
\end{tabular}

Volume 4 Issue 11, November 2015

www.ijsr.net 


\section{International Journal of Science and Research (IJSR) \\ ISSN (Online): 2319-7064}

Index Copernicus Value (2013): 6.14 | Impact Factor (2014): 5.611

\section{Conclusion}

Diabetic Autonomic Neuropathy is an emerging serious problem, since above discussed approaches have many limitations and are very expensive to own such device. The outputs obtained by above approaches are also not satisfactory to analyze pupil parameters and detect the DAN. The new and novel approaches has to be found to improve effectiveness of the device which can be done by using raspberry pi board and raspberry noir camera. The cost can be reduced by inclusion of open source soft-wares instead of using LABVIEW and MATLAB.

\section{References}

[1] Kristina Herbst, Birgit Sander, Dan Milea, Henrik Lund-Andersen and Aki Kawasaki "Test-retest repeatability of the pupil light response to blue and red stimuli in normal human eyes using a novel pupillometer", PUBMED.gov

[2] Giselle L Ferrari, Jefferson LB Marques, Rajiv A Gandhi, Simon R Heller, Fábio K Schneider, Solomon Tesfaye, and Humberto R Gamba: "Using dynamic pupillometry as a simple screening tool to detect autonomic neuropathy in patients with diabetes",PMC, US national library of medicine.

[3] Ko ML, Chen YY, Ouyang Y, Huang TW, Tsuen BS, Jeng WD, Chiou JC, Ou-Yang M. "Design and analysis of wearable pupillometer for autonomic neuropathy of diabetic pateint",PUBMED.gov

[4] "Pupil monitoring can detect Diabetic nerve damage",http://blog.visivite.com/2014/08/01/pupilmonitoring-device-can-detect-diabetic-nerve-damage/

[5] http://patient.info/doctor/autonomic-neuropathy

[6] Joel Lindsey,"Wearable Device Could Provide Early Detection Of Diabetes-Related Complication", $30^{\text {th }}$ July 2014. 